\title{
How to keep up with the Mental Health Act
}

\section{S. Humphreys, J. P. Kenney-Herbert \& R. V. Cope}

In recent years there has been a marked increase in the proportion of individuals with mental disorders detained in hospital involuntarily, compared to those admitted on an informal basis (Wall et al, 1999). There is also growing concern about legally incompetent patients being treated under the doctrine of necessity (Eastman \& Peay, 1998). The rise in the numbers of detained patients may have come about for a variety of reasons. Suggested possible contributory factors include a reduction in psychiatric hospital beds; the move towards community care and the consequent tendency to maintain patients at home for longer; increasing comorbidity and more severely disturbed behaviour on hospital wards; and a greater number of individuals transferred to hospital care from the criminal justice system (Mental Health Act Commission, 1999). Statutory mental health legislation in the UK has remained essentially unchanged, in some cases, for nearly 15 years. There have been additions and amendments during that period, as well as new law. For instance, the Mental Health (Patients in the Community) Act 1995, dealing with the care and treatment of people with mental disorders, and the Criminal Evidence (Amendment) Act 1994, covering specific issues to do with certain groups of those suffering from psychiatric disorders. Despite this there is clear evidence from recent research from various parts of the UK that medical practitioners, most particularly psychiatrists, and even those using the Mental Health Act on a day-to-day basis, do not necessarily possess a detailed knowledge of the law. Among a random sample of Section 12(2) approved medical practitioners in the West Midlands, none of those interviewed was able to define the term mental disorder as used in the Act, and only just over onethird correctly identified the four legal categories of mental illness, mental impairment, severe mental impairment and psychopathic disorder (Bhatti et al, 1999). In similar studies undertaken in Scotland, only one in 10 of a national sample of consultant psychiatrists was able to give the statutory definition of the term mental disorder (Humphreys, 1998) and among a similar non-consultant sample only $28 \%$ were able to give the correct title and year of the Mental Health (Scotland) Act 1984 (Humphreys, 1997). It would seem important, therefore, that psychiatrists do not become complacent about their knowledge and use of the Act, even though there has been considerable debate around the issue of how much expertise and precise factual knowledge of specific legislation is actually required.

Why should psychiatrists know and understand the law as it relates to the care of individuals with mental disorders? The question might be more appropriately posed the other way round, namely, why should they not know the law? For some people suffering from certain forms of mental disorder, involuntary detention and compulsory treatment are major and important means of access to the care that they require. The law also serves to protect the rights of those made subject to formal measures, as well as clinicians and others involved in their treatment. It might be argued that knowledge of the Mental Health Act and its proper use is as fundamental to many branches of psychiatry as the correct understanding and appropriate initiation of physical investigations, therapies or practical

Martin Humphreys is Senior Lecturer in Forensic Psychiatry in the University of Birmingham and Honorary Consultant Forensic Psychiatrist at the Reaside Clinic (Birmingham Great Park, Birmingham B45 9BE). He has a particular research interest in mental health law and statutory follow-up of mentally disorderd offenders, as well as the clinical care and treatment of female prisoners. Jeremy Kenney-Herbert is Consultant Forensic Psychiatrist at the Reaside Clinic, and Honorary Senior Clinical Lecturer, University of Birmingham. His research interests include mental health law and service delivery. Rosemarie Cope is Consultant Forensic Psychiatrist and Clinical Director of the Reaside Clinic, and Honorary Senior Lecturer, University of Birmingham. Her research interests include ethnic issues in forensic psychiatry. 
procedures in any other branch of medicine. In one very widely publicised case of homicide, committed by a detained patient with mental illness, misunderstanding and lack of knowledge of mental health legislation played a part in the circumstances leading to the death of a member of staff (BlomCooper et al, 1995). A young man with a schizophrenic illness, who was subject to Section 3 of the Mental Health Act 1983 (a substantive treatment order), was being granted leave from the hospital where he was a patient by members of nursing staff, with no reference to the responsible medical officer. On one of these occasions he purchased a knife and on returning he killed an occupational therapist. In the ensuing inquiry it was clear that failure to use the proper provision for leave from hospital under Section 17 of the Mental Health Act 1983 had obviously been a significant factor.

The law is one area where psychiatrists may be cross-examined, most frequently at the time of a mental health review tribunal, but sometimes in court. It is necessary to have a clear understanding and knowledge of original grounds for detention, whether they are still fulfilled, what issues the tribunal might be required to address and the questions they or the patient's legal representative might ask. All of this requires knowledge of the relevant Act. There is reason then for psychiatrists to know the law. Understanding can only come with use, but familiarity should not be allowed to breed contempt.

\section{Royal College of Psychiatrists' training pack}

In 1997, the Royal College of Psychiatrists produced a training pack entitled Using the Mental Health Act. A Training Resource for Doctors. In the introductory notes it states that "a working knowledge of the Mental Health Act ... is vital to enable psychiatrists to function effectively in today's mental health services". The pack contains comprehensive summary information about use of the various parts of the Mental Health Act, including the detention and care of formal patients, consent to treatment, mental health review tribunals, the Care Programme Approach (CPA) and risk assessment. It encompasses both statutory legislation and, where relevant, case law, as well as clinically important associated areas. It also gives guidance on some relevant areas of the Police and Criminal Evidence Act 1984, and the Sex Offenders Act 1997. It has a glossary and a quiz on the Mental Health Act 1983. In addition, there is a training video, which includes simulated mental health assessments with associated comments and questions at various intervals and time for discussion. The pack includes details of how to plan a training session using the video, summaries of the case scenarios and a set of overhead projector slides to be used in seminar teaching. It is an invaluable educational tool.

The National Confidential Inquiry into Suicide and Homicide by People with Mental Illness (1999) has emphasised the importance of training in use of the Mental Health Act in relation to the reduction of suicide, self-harm and homicide by people with mental disorders. In producing its training pack, the Royal College of Psychiatrists has acknowledged public interest in the difficulties of the management of people with mental disorders and the need to improve professionals' knowledge and understanding of mental health legislation. Although it may be difficult to establish an evidence base for the use of the Mental Health Act, doctors who are engaged in psychiatric practice and the care of patients with mental disorders should have an understanding of the theoretical basis of mental health legislation, a firm grounding in sound clinical practice in relation to compulsory detention and treatment and knowledge of the associated ethical issues.

\section{Literature}

Although there is no substitute for reference to the Act itself, there is a wide variety of literature available that addresses both the theoretical and practical aspects of mental health law (Box 1). Books range from those specifically about the Mental Health Act, including guides (Bluglass, 1983), those based around theory and practice in mental health law (Blackie \& Patrick, 1990; Hoggett, 1990; Jones, 1999) and comprehensive and ongoing review (Gostin, 1986). In addition, there have been a number of handbooks produced by pharmaceutical companies (Bethlem and Maudsley NHS Trust, 1983; Schering Healthcare, 1983, 1984). In some texts there are useful and easily understood summary tables of statutory powers and procedures in relation to the care of individuals with mental disorders, which are a helpful and quick guide to various sections and parts of the Mental Health Act 1983, as well as the Mental Health (Scotland) Act 1984 and the Mental Health (Northern Ireland) Order 1986 (Briscoe et al, 1993; Cope, 1995). More recently, work has been published that has sought to approach the issue of review and reform of current mental health legislation from a variety of different standpoints (Eastman \& Peay, 1999). This has succeeded in 
Box 1 Literature sources on the Mental Health Act

Relevant Mental Health Act Associated code of practice Books, including practical guides, theoretical analysis and ongoing review

Pharmaceutical company handbooks

General journals - uncommon

Specialist journals (e.g. Psychiatric Bulletin)

Department of Health systematic review of research relating to the Mental Health Act 1983

highlighting many of the areas that will require attention when new legislation is drafted.

Amendments to the existing law and new legislation are generally subject to review and assessment in academic and peer-reviewed professional publications. There are a small number of specialist journals now dealing with the subject of mental health law and associated issues, which include sections on the Mental Health Act, analysis of relevant cases where these might have an impact on the care of people with mental disorders and associated issues. The Department of Health has recently published a systematic review of research on the Mental Health Act 1983 (Wall et al, 1999).

\section{Code of practice}

The appropriate government department produces a code of practice to accompany the relevant Mental Health Act for all UK jurisdictions. This is intended as a guide and reference source for medical practitioners and others involved in the care and treatment of people with mental disorders. It supplements the legislation itself and also gives guidance in related areas, such as those concerned with patients presenting particular management problems, the possible need for physical restraint, the use of locked and secure areas and seclusion, as well as psychological treatments and a broad outline of procedures for dealing with complaints.

\section{The internet}

There are many other sources of information available on mental health law (Box 2), including the internet. Sites exist for the UK and further afield. These include the Royal College of Psychiatrists, the Department of Health, the Home Office and others. They provide up-to-date information on publications,
Box 2 Other sources of information on the Mental Health Act

The internet

Mental Health Act Commission, Mental Welfare Commission, etc. Government departments

NHS trusts

Continuing professional development

case law, research, the current review process and associated discussion documents. A search on 'mental health law' is likely to yield several hundred possible sites.

\section{Statutory independent bodies}

The Mental Health Act Commission (MHAC) and the Mental Welfare Commission for Scotland intermittently publish guidelines on various aspects of the law and its interface with psychiatry, including the operation of the appropriate Mental Health Act. They also address wider issues, including the interpretation of terms and aspects of the Code of Practice (e.g. MHAC Practice Note 3: "Section 5(2) of the 1983 Mental Health Act and transfers"; MHAC Practice Note 4: "Section 17 of the Mental Health Act"). These bodies also produce regular reports that include figures for the use of the relevant Act.

\section{Government departments}

The Home Office issues circulars in relation to a wide variety of legal provisions, some of which affect the care of those with mental illness. These are not confined to mental health legislation specifically, but may include other statutory law that may affect, for instance, mentally disordered offenders (Criminal Evidence (Amendment) Act 1997). The Home Office Statistical Bulletin not infrequently includes data that relate to patients detained under Part III of the Mental Health Act.

The Department of Health publishes annual statistics on the use of the Mental Health Act and raises topical issues on those of particular concern. A recent example is guidance issued relating to visits by children to patients in psychiatric hospitals.

\section{Case law}

Case law may be important in the interpretation of statutory legislation, and mental health law is no 
exception. In particularly important cases, such as $\mathrm{R} v$. Bournewood Community and Mental Health NHS Trust ex part L, information and analysis will be readily available. On other occasions a more careful search of specialist journals, or reference to other sources, may be necessary.

\section{NHS trusts}

Mental health trusts are required to circulate guidelines and policy documents relating to new provision and the use of current mental health legislation.

They engage the services of solicitors in order to have access to legal advice on a wide range of matters. Comment and advice should be available from them on issues relating to the use of the Mental Health Act and allied legislation. They should be able to provide an opinion on most areas, particularly those where case law has influenced practice or where statutory provision has been interpreted or clarified in a particular way. They are not only a source of direct information, but can act as a means of access to specialist law journals and other legal practitioners with particular expertise in specific areas.

\section{Continuing professional development}

Continuing professional development in mental health law and the use of the Mental Health Act is available through a range of different postgraduate educational opportunities. These vary from locally organised academic programmes including clinical case conferences, through legal briefings, to sessions or study days designed specifically to address Mental Health Act matters and whole-day or residential courses run by specialist consultancies or organisations with a particular remit to teach mental health law and related issues. The British Association of Mental Health and Law has recently been founded and held its first annual meeting in Nottingham in October 1999.

\section{Approval procedures for medical practitioners under the Mental Health Act}

For England and Wales there are Department of Health guidelines on the procedures for the approval and reapproval of medical practitioners under Section 12(2) of the Mental Health Act 1983. These courses, which are now organised in all regions of England, constitute an important opportunity to obtain initial and refresher training in the use and operation of the Mental Health Act. They are not confined to those seeking approval or reapproval at any particular time. Their content and length varies considerably across the country, but they are the responsibility of the appropriate Section 12(2) approval panel.

\section{Research}

With a major review of mental health legislation likely throughout the whole of the UK, there has been an increasing interest in research into many different aspects of the law and its impact on the care and treatment of people with mental disorders. As part of a major programme of research into the operation of the Mental Health Act 1983, the Department of Health has recently published a systematic review of research relating to it (Wall et al, 1999). This is an important source of information for those seeking an evidence base for their practice in relation to use of the legislation. It provides a comprehensive picture of available findings on both practical and theoretical matters pertaining to the Act, as well as an analysis of trends in its use over recent years. It includes reference to review and commentary but concentrates on the detail of datacontaining papers, giving a resumé of each. It also identifies a number of important areas where no research has yet been undertaken. Although its usefulness may be limited with the advent of new legislation, it still gives invaluable pointers to sources of information about good practice and the starting points for future research.

\section{Conclusion}

The Mental Health Act 1983 bestows upon medical practitioners the power to override the basic autonomy of individuals with mental disorders in certain circumstances. The onus is upon the medical practitioner to maintain an adequate and up-to-date knowledge of the relevant legislation, its underlying principles and best practice in its use and interpretation. Such understanding will protect the rights of those with mental disorders, as well as, in certain circumstances, increasing the efficacy of psychiatric intervention. Review of current legislation is underway in the UK and reform will follow. With new law it will be particularly important for psychiatrists to remain well informed in this area. There is a wide variety of readily available sources of information already and a growing interest, particularly in the area of research. 


\section{References}

Bethlem and Maudsley NHS Trust (1983) Mental Health Act 1983 Guidelines. London: Bethlem and Maudsley NHS Trust.

Bhatti, V., Kenney-Herbert, J., Cope, R., et al (1999) Knowledge of current mental health legislation among medical practitioners approved under Section 12(2) of the Mental Health Act 1983 in the West Midlands. Health Trends, 30, 106-108.

Blackie, J. \& Patrick, H. (1990) Mental Health. A Guide to the Law in Scotland. Edinburgh: Butterworths.

Blom-Cooper, L., Hally, H. \& Murphy, E. (1995) The Falling Shadow: One Patient's Mental Health Care 1978-1993. London: Duckworth.

Bluglass, R. (1983) A Guide to the Mental Health Act 1983. Edinburgh: Churchill Livingstone.

Briscoe, O., Carson, D., d'Orban, P., et al (1993) The law, adult mental disorder and the psychiatrist in England and Wales. In Forensic Psychiatry. Clinical, Legal and Ethical Issues (eds J. Gunn \& P. J. Taylor), pp. 21-117. Oxford: Butterworth Heinemann.

Cope, R. (1995) Mental health legislation. In Seminars in Practical Forensic Psychiatry (eds D. Chiswick \& R. Cope), pp. 272-309. London: Gaskell.

Department of Health \& Welsh Office (1999) Code of Practice. Mental Health Act 1983. London: Stationery Office.

Eastman, N. \& Peay, J. (1998) Bournewood: an indefensible gap in mental health law. British Medical Journal, 317, 94-95.
— \& Peay, J. (1999) Law Without Enforcement. Integrating Mental Health and Justice. Oxford: Hart Publishing.

Gostin, L. (1986) Mental Health Services - Law and Practice. London: Shaw and Sons.

Hoggett, B. (1990) Mental Health Law. London: Sweet \& Maxwell.

Humphreys, M. S. (1997) Non-consultant psychiatrists' knowledge of emergency detention procedures in Scotland. A national survey. Psychiatric Bulletin, 21, 631-635.

- (1998) Consultant psychiatrists' knowledge of mental health legislation in Scotland. Medicine, Science and the Law, 38, 237-241.

Jones, R. M. (1999) Mental Health Act Manual. London: Sweet \& Maxwell.

Mental Health Act Commission (1999) The Mental Health Act Commission Eighth Biennial Report 1997-1999. London: Stationery Office.

National Confidential Inquiry into Suicide and Homicide by People with Mental Ilness (1999) Safer Services. London: Department of Health.

Royal College of Psychiatrists (1997) Using the Mental Health Act. A Training Resource for Doctors. London: Royal College of Psychiatrists.

Schering Healthcare (1983) A Guide to the Mental Health Act 1983 and Allied Legislation. Burgess Hill, Sussex: Schering Healthcare.

- (1984) A Guide to Parts of the Mental Health (Scotland) Act 1984 and Allied Legislation. Burgess Hill, Sussex: Schering Healthcare.

Wall, S., Churchill, R., Hotopf, M., et al, (1999) A Systematic Review of Research Relating to the Mental Health Act 1983. London: Department of Health.

\section{Commentary}

\section{Fred Browne}

Although practitioners will be most familiar with the mental health legislation in their own jurisdiction, there can also be value in studying other legal frameworks. I give here a perspective from Northern Ireland.

The central piece of mental health legislation in Northern Ireland is the Mental Health (Northern Ireland) Order 1986 (hereafter, the Order). The Order has been closely modelled on the Mental Health Act 1983 of England and Wales and the Mental Health (Scotland) Act 1984. However, the Order has unique and distinctive features that differentiate it from the mental health legislation in England, Scotland and Wales. The Order is also substantially different from the Republic of Ireland's Mental Treatment Act 1945.
Particularly at the present time, when reform of mental health legislation is being considered, it is important to be aware of these differences between the different jurisdictions and to assess their advantages and disadvantages.

\section{Features of the Mental Health (Northern Ireland) Order 1986}

It is not possible in a short article such as this to list all of the different features of the Order, but the following are among the more notable.

Fred Browne is a Consultant Forensic Psychiatrist at the Knockbracken Healthcare Park, Belfast BT8 8BH. His research interests include mental health legislation and service development. 